


\section{Fritifche Gejamtausgaben Eljäfiijher Schriftfteller des Mittelalters und der Reformationszeit veröffentlicht}

von der Gejellichaft für eljäfijiche Literatur

\section{đhomas Aturners Meut/dhe \$dhriften} mit den Бolzichnitten der Erjtorudke berausgegeben unter Mitarbeit von

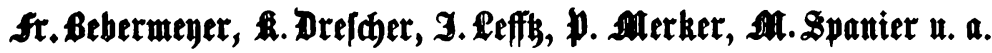
von

Sranz Schultz

Band IX

Straf̧burg

Verlag von karl $\mathrm{J}$. Trübner

1918 


\title{
Chomas Aluture
}

\section{Don Dem großen $\mathbb{P}$ nttheri/den $\mathfrak{H a r r e n}$}

\author{
Бerausgegeben \\ von \\ Dr. Paul Merker \\ a. o. Profeffor an der Univerfität Leipzig.
}

Strafburg

Verlag von Farl ]. Crübner

1918 
Alle Rechte vorbebalten.

m. DuMont Shauberg, Strasburg. 